\title{
Motor Ocular Neuropathy Caused by Mefloquine
}

Suzana Kovačević ${ }^{1 *}$, Samir Čanović1, Ana Didović Pavičić1, Marija Škara Kolega ${ }^{1}$, Ana Oštrić Brnjac ${ }^{1}$ and Miro Morović ${ }^{2}$

${ }^{1}$ Department of Ophthalmology, Zadar General Hospital, Zadar, Croatia

${ }^{2}$ Department of Infectious Diseases, Zadar General Hospital, Zadar, Croatia

\begin{abstract}
Mefloquine is widely used for prophylaxis and treatment of malaria. It can induce a range of neurological side effects and its' neurotoxic potential with neuron apoptosis and significant axonal degeneration was confirmed in several in vitro studies. We report a patient presented with rare symptoms of relapsing motor neuropathy involving extraocular muscles, primary $m$. levator palpebrae, occuring while the mefloquine treatment.
\end{abstract}

Keywords: Mefloquine; Malaria; Mefloquine toxicity; Ophtalmic neuropathy

\section{Case Report}

Mefloquine is an oral medication used for treatment and prevention of malaria [1]. Among subjects who recived mefloquine for prophylaxis the most frequently observed side-effects are vomiting, dizzines, syncope, extrasystoles; among those who recieved the drug for treatment the most common adverse reactions are dizzines, myalgia, nausea, fever, headache, vomiting, diarrhea, skin rash etc. The most serious and permanent adverse side-effects observed were psychiatric disorders, sensorimotor perypheral neuropathy, vestibular imbalance and central nervous system disorders [2].

Experimentally it was found that neurogical damages caused by mefloquine could be due to block of connexin molecules in the brain, the proteins that play role in movement, vision and memory $[3,4]$. More over, recently it was shown that mefloquine can cause axonal degeneration by disrupting the cellular redox environment which induce oxidative stress in nerve fibers $[5,6]$.

A fifty-two year old male came for an examination with symptoms affecting upper lids. During more than last three years he suffered from intermittent attack of upper lids fasciculations, from few times a day to every one to two hours, every attack lasting for about twenty seconds. In the last year he also occasionally had cramps in upper lids, lasting for two to three seconds, several times a day. He had no visual acuity loss, no pathologic findings in ophtalmologic examination.

He went through the neurologic examination, EEG and MRI, with no pathologic findings. In his medical hystory we found out that the patient had recurrent attacks of tropical malaria, ten times during the last six years, as a result of working in an endemic area of malaria (Nigeria) for several years. During the last three years he was treated several times with meloquine alone or sometimes with artemisin, as a treatment option for semi-immune persons. He used the last dose of mefloquine 6 months prior to this examination. In the time he first noticed the symptoms, he was not using the therapy but few months prior to the onset. Since there were no other patologic findings, ocular or general, and considering patient medical history, we concluded that the symptoms were mefloquin related. Therefore, we recommended mefloquin exclusion in the future and regular check-up to determine severity and reversibility of mefloquin damage. Follow-up during the next year showed no recurrence of ocular neuropathy.

Mefloquine is a 4-quinolonmethanol group drug. At prophylacitc doses use, risk of serious toxicity is about 1 in 10,000 patients. Higher therapeutic doses associated usually with significantly higher rate of
CNS events (e.g. nausea, dizzines, fatigue, mental confusions and sleep loss); psychosis, encelophathies and convulsions are seen in 1 in 12001700 patients [7].

There are documented cases of mefloquine toxicity on eyes, causing retinopathy end maculopathy, caused by tendency of the drug to accumulate in the retinal pigment epithelium and exert toxic effects $[8,9]$.

As mentioned above, in vitro investigations explained the most frequent mechanisms of neuronal and axonal injurie caused by mefloquine [3-6].

It is known that most antimalarial drugs (mefloquine, quinacrine, primaquine, chloroquine, amodiaquine) produce phototoxic cutaneous and ocular effects, icludind disturbances in skin pigmentation, corneal opacity, cataract formation and severe retinopathy [8]. In this regard, a case of severe maculopathy during the quinacrine prophylaxis [9]. Also, a case of sudden trigeminal sensory neuropathy affecting lips is described [10].

Our patient is presenting with symptoms of motor neuropathy involving extraocular muscles, upper lid retractors, primary $m$. levator palpebrae while using therapeutic doses of mefloquine.

Neuropathies have been documented in individuals taking mefloquine, but not involving extraocular muscles.

There were two reported cases of motor polyneuropathy, involving both upper and lover limbs, presened with skin changes (erithematous rash and dermatitis), with progressive weakness and inability to preform fine motor acctivities, after first exposure to mefloquine [2]. In both cases there was a full recovery without any residual deficit at the 3-month follow up.

To our knowledge this is the first case of extraocular muscles motor neuropathy in a patient treated with mefloquine.

*Corresponding author: Suzana Kovačević, Zadar General Hospital, Bože Peričića, 523000 Zadar, Croatia, Tel: 00385-23-315677; Fax: 00385-23-312724; E-mail: suzana.kovacevic@zd.t-com.hr

Received May 15, 2014; Accepted October 20, 2014; Published October 30, 2014

Citation: Kovačević S, Čanović S, Pavičić AD, Kolega MŠ, Brnjac AO, et al. (2014) Motor Ocular Neuropathy Caused by Mefloquine. Gen Med (Los Angel) 2: 150 doi: 10.4172/2327-5146.1000150

Copyright: () 2014 Kovačević S, et al. This is an open-access article distributed under the terms of the Creative Commons Attribution License, which permits unrestricted use, distribution, and reproduction in any medium, provided the original author and source are credited. 